\title{
Walter Hayle Walshe (1812-1892) and his book Diseases of the Heart
}

Department of Cardiology, Royal North Shore Hospital, St Leonards, New South Wales, Australia

G E Bauer

Correspondence to Dr G E Bauer Department of Cardiology, Royal North Shore Hospital, St Leonards, NSW 2065, Australia.

Accepted for publication 5 December 1991

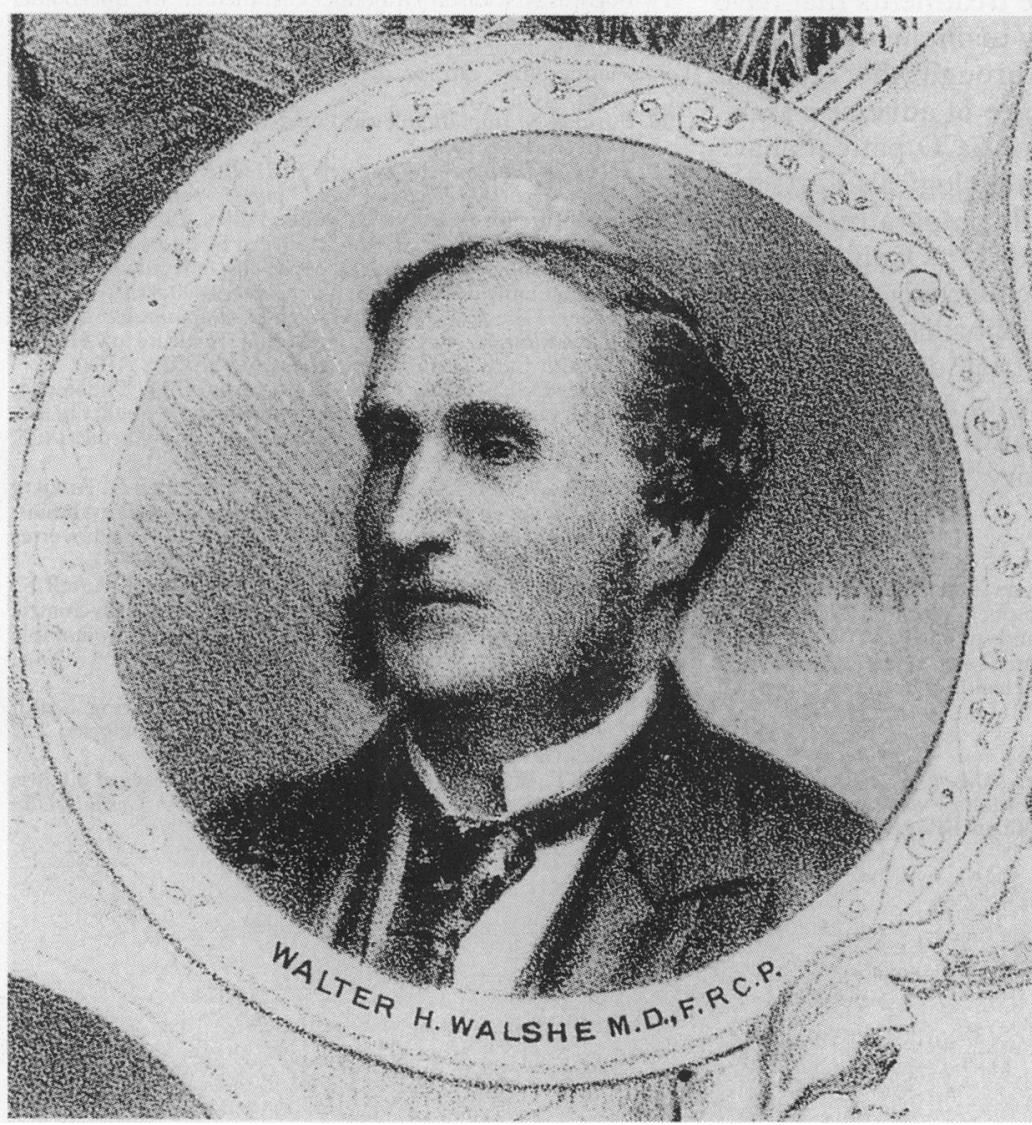

Walter $H$ Walshe, MD, FRCP. From a Lithograph: Memorial of University College Hospital by $H$ Hall, by courtesy and with permission of the Wellcome Institute Library, London. retirement, make Walshe an individual worthy to be rescued from oblivion. His Diseases of the Heart, which first appeared in 1851 and reached the peak of popularity with the fourth edition published in 1873 , deserves to rank with the works of James Hope, William Stokes, and Austin Flint as the important cardiology texts of the preMackenzie era.

\section{Walter Hayle Walshe}

Walter Hayle Walshe was born in Dublin on
Walter Hayle Walshe distinguished physician, author, and scholar, contemporary of Queen Victoria (1819-1901) and Charles Dickens (1812-1870) is one of the neglected forerunners of the great British cardiologists of the early twentieth century. His unconventional and peripatetic undergraduate days, followed by academic pre-eminence and rounded off by an extended, varied, and rewarding

Laennec. Walshe's teachers included the surgeon Baron Guillaume Dupuytren to whom he was apprenticed as surgical dresser contemporaneously with Oliver Wendell Holmes. He served his medical clerkship at the Hotel Dieu and attended ward rounds at $\mathrm{La}$ Charite. In 1834 he joined the service of the master clinician Phillipe Charles Alexandre Louis at La Pitie. He was introduced to a new scientific and statistical approach to medical diagnosis and treatment and embraced the need for the detailed appraisal of all relevant clinical observations. The application of these methods to the study of diseases such as phthisis and enteric fever led to a better understanding of their cause, management, and outcome.

Intending to take his medical degree in an English-speaking institution, Walshe, in 1835 , moved to Edinburgh and graduated from that university in the following year. He returned to Paris for a brief period but in 1838 settled in the north of London to take up general practice. His main interest remained the study of pathology and scientific investigation of medical problems. In the next two years he became a prolific writer contributing original observations on diverse subjects including malignant disease, pulmonary tuberculosis, empyema, and subdural haematoma. His articles attracted attention and led to his appointment, in 1841 at the age of 29 years, as Professor of Morbid Anatomy at University College London, in succession to Sir Robert 
Carswell. There he was not only part of a strong medical team but also maintained a lively interest in the activities of the faculty of Arts. In 1846 he was appointed Holme Professor of Clinical Medicine and became physician at University College and Brompton Hospital for Diseases of the Chest. Two years later he reached the pinnacle of his academic career when he took up the position of Professor of the Principles and Practice of Medicine succeeding C J B Williams. In absolute charge of medical teaching at University College Hospital he delivered "clinical lectures" as well as the "systematic course".

Walshe proved to be a gifted and meticulous teacher. His lectures and articles were based on carefully recorded personal experiences and a thorough knowledge of the literature. Facts were presented on the basis of numerical and statistical details and conclusions arrived at by a process of logical deduction and exclusion. His students appreciated and admired his ability to simplify complex concepts by presenting the core and essentials of the problem under discussion.

Walshe retired from his academic duties in 1862 , at the early age of 50 years, to be succeeded by Sir William Jenner. He had attained an international reputation and membership of medical societies in Paris, Copenhagen, and Athens. He became a successful consultant physician and was in great demand as an expert witness in medico-legal disputes, putting to good use his legal training. He married late in life and devoted the last decade to publishing books on subjects not related to medical practice but amplifying experiences gained during his early years at the Sorbonne, such as Dramatic Singing Physiologically Estimated (1881) and The Colloquial Linguistic Faculty and its Physiological Groundwork (1885). A revealing and moving comment on Walshe's final years was published by a colleague: "That his exquisitely sensitive nature under the influence of physical pain, was apt to take a materialistic and pessimistic view of things must be well known to his friends, but this was but a symptom of his suffering".

Anticipating the discovery of myxomatous, billowing mitral valve by a century, Walshe wrote "may it be that defect in the elastic tissue, which seems to have been shown by W O Markham to exist in the valves, allows their eversion into the auricle". It is of interest that W O Markham, assistant physician to St Mary's Hospital, published in 1853 a translation of the 1850 fourth edition of Joseph Skoda's $A$ Treatise on Auscultation and Percussion. Who then, first described mitral valve prolapse?

\section{Diseases of the Heart}

The book $A$ Practical Treatise on Diseases of the Heart and Lungs, including the Principles of Physical Diagnosis was published in 1851 and dedicated to Walshe's teacher P C A Louis. A second edition followed in 1856 (thereafter the book was divided into two parts) the third edition devoted to diseases of the heart appeared in 1862, and the fourth and last in 1873.

Walshe's book rapidly gained the reputation of being "one of the most careful and elaborate epitomes of knowledge in the matters with which it deals". ${ }^{2}$ The foreword to the fourth edition contained prophetic words when it mentioned "medical and surgical means of successfully controlling the progress of structural diseases of the heart and great vessels".

Part I deals in detail with the clinical examination of the heart and blood vessels under the traditional headings of inspection, palpation ("application of the hand"), percussion, and auscultation. Percussion and auscultation were clearly inspired by Leopold Auenbrugger, whose writings on percussion were rescued from obscurity by Corvisart's translation from German to French and by Laennec, the inventor of indirect auscultation: both were dominant personalities during the first half of the nineteenth century.

Walshe's description of the physical signs and pathological findings in valvar heart disease was the result of close observation rounded off with personal speculation. He was one of the first to stress the presystolic timing of the thrill and murmur of mitral stenosis and he noted that the impulse may be regular or irregular in force or rhythm and, being unaware of the existence of atrial fibrillation, he wrote "in all probability the irregularity when present is in the main neurotic". He stated that in patients with mitral regurgitation a systolic thrill may sometimes be felt "at or about the left apex ... but the essentially distinctive sign of this regurgitation is a systolic left apex murmur".

He described the post-mortem demonstration of mitral regurgitation: "Tie the aorta and coronary arteries, cut off the apex of the heart and let fall against the mitral valve a full-sized column of water; the valve will either support the water or allow it to pass through to the auricle. If the whole of the ventricle above the floor formed by the valve remains filled with water, scarcely a drop filtering through, there can be no doubt the valve was competent during life."

Part II discusses individual conditions under the headings of dynamic and organic diseases. Walshe described Heberden's angina pectoris as a rare affection, but pseudo-angina "a condition which I almost daily meet." More akin to present-day concepts are the statements: "The cardinal fact in the prognosis of real angina under any circumstances is its incertainty", and "Has Angina Pectoris any anatomical character? In all the cases I have opened there was more or less calcification with contraction of the coronary arteries."

He recorded small contracted pupils in patients with aneurysms of the arch of the aorta, no doubt referring to Argyll Robertson pupils of syphilitic heart disease. He described in detail the examination of coarctation of the aorta: "Not the least important and readily ascertainable of the physical signs are presen- 
ted by the extreme pulsations of the carotid, subclavian, temporal, deep cervical (? common carotid) and intercostal arteries. Occasionally local expansile impulses aneurismal to the feel but sometimes strong enough to gradually wear away the ribs, may be felt from place to place in the latter vessels". An illustration of the collateral arterial circulation produced but unpublished by his predecessor Carswell appears in the book.

How does Walshe's work compare with that of his predecessors and contemporaries?

James Hope, eleven years his senior, was a brilliant experimental physiologist whose career was cut short by his premature death due to pulmonary tuberculosis. His contributions to the understanding of valve incompetence and heart failure, based on animal work, remain milestones in the history of cardiology. Hope was innovative while Walshe was more inclined towards meticulous observation and detailed analysis. Octavius Sturges, writing in the Lancet summarised the views held at the time of Walshe's death: "He differs from Stokes and from Sibson occasionally and with much respect, from Skoda more often and not unwillingly, from Hope always and with joy". ${ }^{3}$

1 X.Y. The Late Dr Walshe. Lancet 1892;ii:1531-2.

3 Sturges O. The Late Dr Walshe. Lancet 1892;ii:1467. 